\title{
Entrevista con Carlos Guillermo Wilson
}

Introducción: Esta entrevista se celebró el 18 de junio de 2014 en El Cajón, CA, en la casa de Carlos. Es el resultado de muchos años de conversaciones, las cuales empezaron en octubre de 1998 cuando lo contacté por correo electrónico con motivo de presentarme. Acababa de terminar la tesis doctoral en la que estudié a fondo las novelas Chombo y Los nietos de Felicidad Dolores junto con Chambacú, corral de negros y Changó, el gran putas, del colombiano Manuel Zapata Olivella. En julio de 1999 tuve la suerte de conocer a Carlos en persona en la Ciudad de Panamá donde los dos nos habíamos reunido para discutir sus obras en ocasión del Primer Congreso Internacional de Literatura Panameña. Después del congreso nos quedamos en vernos otra vez, pero las exigencias del trabajo no nos permitieron hacerlo hasta en la fecha indicada arriba. Huelga decir, dada su condición de salud en ese año, que ambos hubiéramos preferido una reunión más temprana, pero en esta vida las cosas ocurren en la forma en que ocurren por una razón. Sólo concluyo al decir que, con el paso de los años, llegué a cobrarle mucho cariño y admiración a Carlos y él a mí, y de ahí los títulos "Wofa" y "Maabiinu", que el lector va a encontrar en lo que sigue. "Wofa" significa, "Tío" en el idioma Akan de Ghana. "Maabiinu" es el nombre que me pusieron mis padres en la lengua "Sisaali" del noroeste de Ghana-mi idioma materno. Como con todas entrevistas, he tenido que modificar un poco el contenido de las respuestas de Carlos para asegurar la claridad de comprensión.

HZ: Gracias por concederme esta entrevista, Wofa. Es un verdadero honor poder conversar en persona contigo sobre tus libros. Aunque hemos tenido la oportunidad de hacerlo múltiples veces en nuestras pláticas telefónicas, no es lo mismo que sentarnos cara a cara para seguir esa conversación. Es un honor incalculable. Quisiera empezar la charla de hoy, preguntándote, ¿cómo te sientes ahora en términos de salud? Como muchos de tus lectores ya saben, no has estado bien desde 2005 cuando te descubrieron el tumor cerebral. Me gustaría que les dieras alguna noticia alentadora para que sigan teniendo fe y esperanza en tu recuperación.

CGW: Pues, mejor que al principio del incidente. Aunque me quedé paralizado en el lado izquierdo del cuerpo y tuve que usar una silla de ruedas por muchos meses, nunca perdí el habla. Solamente perdí la elocuencia porque ahora tengo que buscar las palabras en algún rincón de la mente. Lo llamamos el cancaneo en Panamá-cuando pausas para buscar las palabras adecuadas en una conversación. Por lo tanto, no te sorprendas si hago breves pausas antes de contestar a tus preguntas. Otra mejora es el hecho de que ya no uso una silla de rueda. Sólo uso el bastón que ves y a veces la andadera que tengo en la sala para mayor seguridad. Me facilita caminar a cortas distancias sin peligro de caerme porque me he caído más de veinte veces, y los doctores temen que las caídas me provoquen hemorragias en el cerebro. Termino al agradecerte a ti también por venir de tan lejos para realizar esta entrevista. Aunque mi condición física ha mejorado a lo largo de los años, yo sospecho que ésta va a ser mi última entrevista porque pronto voy a cumplir 75 años y cada nuevo día es un regalo del Señor.

HZ: Hablemos de tus libros. Empezaste con Los Cuentos del Negro Cubena (de aquí en adelante Cuentos) en 1977, seguido por El Pensamiento del Negro Cubena en 1978. Tres años más tarde, en 1981, publicaste tu primera novela Chombo, la cual fue seguida por Los Nietos de Felicidad Dolores (de aquí en adelante Nietos) en 1991. En 1994, comenzaste a escribir Los sueños ancestrales, título que cambiarías posteriormente a La misión secreta (de aquí en adelante Misión). Estabas trabajando sobre ese libro cuando te enfermaste. Puesto que el objetivo 
principal de todas esas obras es llamar la atención del mundo a las injusticias que ha sufrido la gente de ascendencia negra en las Américas desde su llegada a estas tierras, ya sea en Panamá o en otras partes del continente, ¿cuánto éxito dirías que has tenido en los treinta y siete años que llevas librando esa batalla?

CGW: Bueno, realmente, es una odisea que afortunadamente a mí me tocó poner por escritola esencia y el espíritu de este grupo. Yo soy descendiente de los africanos que fueron capturados, esencialmente en el área que hoy conocemos como la Costa de Marfil, Ghana, Nigeria y el Congo. Entre ellos se hallaban a veces niños y niñas de apenas 7 o 10 años, y los barcos negreros tardaban hasta tres meses para llegar a los puertos negreros de Cuba y La República Dominicana desde donde los repartían a las otras islas del Caribe_-Granada, Barbados, Jamaica, Santa Lucía, Dominica, Haití, etc. Como pertenecían a distintos grupos étnicos, no hablaban el mismo idioma y fueron forzados, primero, a abandonar sus lenguas originales y, luego, a formar un mestizaje o una amalgama cultural. Yo soy producto de esa mezcla. Como ya sabes, mi abuela Nenén llegó a Panamá desde Jamaica, y mi abuelo Papá James vino de Barbados. La pérdida de sus idiomas fue tal vez el daño psicológico más profundo que sufrieron aquellos ancestros, pero gracias a su empeño y creatividad, fueron forjando nuevas formas de comunicación que les permitieron combatir la pérdida lingüística y crear nuevas comunidades.

HZ: ¿Entonces la expresión lingüística de sus descendientes sigue siendo la manifestación más palpitante de los vínculos que tienen con África?

CGW: Pues, claro. Y eso me ha dado a mí materia en mis libros para tratar de enfocarme en la comunicación entre grupos que por razones históricas aprendieron una lengua que ya no era ni francés, ni inglés, ni español. Era una nueva lengua, una amalgama con expresiones que tenían en su vocabulario africano que todavía se nota en bailes como la bamba veracruzana en México. Eso es tan africano como la cumbia panameña, la cual originó en la región de donde yo soy porque nací en 1941 en la Ciudad de Panamá y nuestra música se conocía alrededor del mundo. Tanto en la bamba como en la cumbia se ve un espíritu que refleja la joie de vivre o la alegría que heredamos de África. Demuestran, en esencia, que la cultura africana sabe expresar lo que es vivir con paz y alegría. En los bailes de la bamba y la cumbia se ve un canto a la vida, una aceptación de la esencia del ser humano. En cuanto a nuestro modo de hablar, yo me maravillo de cómo fue posible todo eso. ¿Cómo se desarrollaron las distintas lenguas que hoy día se escuchan a lo largo de nuestro planeta? ¿Cómo se inventaron sin computadoras o diccionarios? Y eso está sobrentendido que esa fascinación la expreso constantemente en mi vida personal. He estudiado más de una docena de lenguas porque son la manifestación más maravillosa del ser humano. No sirven solamente para comunicarnos sino también para disimular mensajes. El mejor ejemplo lo ofrecen los soldados navajos durante la Segunda Guerra Mundial, quienes, como habrás oído, confundían a los japoneses al comunicar los mensajes del Ejército Norteamericano y sus aliados en su idioma. Quienes no entiendan esos códigos dirán que son tontos o que hablan de manera ridícula, pero ignoran que se trata de una estrategia.

HZ: Entonces la amalgamación lingüística, en tu opinión, ha ido más allá del propósito de comunicación. También es una forma de defensa.

CGW: Claro que sí. El ejemplo de los indios navajos lo confirma, pero también existe el caso de los negros congos de la costa Atlántica de Panamá, quienes, al igual que los navajos, se comunican en ciertas circunstancias sirviéndose de códigos secretos. Ellos tienen un vocabulario que aún no han estudiado los expertos para descifrar la plenitud de su psicología. Ahora, en el subgrupo al que yo pertenezco, los panameños de ascendencia afroantillana, tenemos nuestro propio acento como consecuencia de la mezcla de los diferentes idiomas caribeños inclusive, los oficiales. Aún recuerdo muy bien palabras que usaba mi abuela Nenén. Por ejemplo, si quería regañar a mi hermana, le decía: "Cho pickney, don't play with dat maga gial!" No creo que lo esté diciendo lo suficientemente fuerte, pero "Cho" significa más o menos "¡Rayos!" mientras "pickney" quiere decir "niño" o niña". Por su parte, "maga" significa "delgada" y "gial" viene de "girl”, entonces la traducción literal de la frase sería algo así como: "¡Rayos, niña, te prohíbo jugar con esa muchacha flaca!" La lección aquí es el hecho de que ella nunca fue a la universidad. Sin embargo, siempre lograba comunicar claramente lo que quería decir sin tener que detenerse para analizar la estructura gramatical de lo que profería. Yo me crié pues, en un hogar multiétnico y multilingüístico. 
HZ: ¿Dirías entonces que los afroantillanos que vinieron de distintas partes de las Antillas a Panamá (Jamaica, Barbados, Haití, Martinica) mantuvieron sus versiones del inglés y el francés como una forma de rebeldía contra el español, el idioma oficial de la República que en las palabras de Jacques Lacan es el "Discurso del maestro"?

CGW: Pues, has atinado en un aspecto muy importante porque desde que zarpó el primer barco negrero de la costa de África, enseguida nos usurparon nuestras religiones ancestrales y hemos sobrevivido en la santería a través de las Siete Potencias. Ya hemos hablado de la bamba y la rumba. Si bien hoy día han pasado a ser parte de bailes y géneros musicales populares, al principio eran manifestaciones religiosas, principalmente, de los esclavos de etnia yoruba, que se servían para recordar las costumbres africanas que dejaron atrás. Esas canciones eran su manera de decir: "Me robaste mi lengua twi, me robaste mi lengua yoruba, me forzaste a hablar tu lengua-el portugués, el español, el francés, el inglés - pero aquí te ofrezco y te regalo mi nueva lengua. Y si tú no la entiendes, es tu problema—allá tú."

HZ: Efectivamente. Compartes el pensamiento de Derek Walcott, quien en un artículo titulado "The Muse of History", describe el inglés caribeño como "una búsqueda nostálgica por la voz perdida del abuelo".

CGW: Sí, sí, claro que lo es.

HZ: Empezaste tus comentarios con la conexión histórica entre los negros caribeños y por extensión los de la América Latina, en general. A mí siempre me ha interesado el tema de la historia, entonces no pude dejar de fijarme en un comentario que hiciste en una entrevista con Elba Birmingham-Pokorny en torno a Nietos, publicada en Denouncement and Reaffirmation of the Afro-Hispanic Identity in Carlos Guillermo Wilson's Workes (Ediciones Universal), donde diste a conocer lo siguiente: "Africa is the source of life, the source of pride that will help Afro-Hispanics cope with the painful reality of daily discrimination; e.g., socioeconomic exclusion, marginalization, and rejection. If the Afro-Hispanic maintains his/her contact with his roots, then and only then will he/she be able to achieve wholeness".

Esa declaración se hizo hace 21 años. ¿̇Aún opinas lo mismo, que en 2014 África sigue siendo la fuente de inspiración para los pueblos, los hijos y los nietos de ese continente en el Nuevo Mundo?
CGW: Pues sí. En Panamá usamos con frecuencia la palabra "cabanga", otro término africano, y raras veces se usa otro término de nostalgia. Es una palabra que expresa con más fuerza el sentimiento de cómo añoramos la esencia de poder comunicarnos en las lenguas africanas-yoruba, congo, ashanti-que se nos borraron, pero siempre terminamos riéndonos porque nos damos cuenta enseguida de que todavía las hablamos, aunque de manera disfrazada (risitas).

HZ: Hablemos de Nietos. Tengo una observación acerca de esa novela. Hacia la conclusión del libro el lector encuentra "Cumbres del Kilimanjaro" (de aquí hacia adelante Cumbres), un espacio ficticio muy similar al pueblo de Ruby en Paradise, la novela de Toni Morrison.Y al igual que Ruby, Cumbres está totalmente libre de blancos, detalle que la galardonada del Nobel explicó de la siguiente manera en una entrevista con el "News Hour with Jim Lehrer" en marzo de 1998: "Isolation and separation are always part of any utopia. And it is my meditation, if you will, and interrogation of the whole idea of paradise as a safe place, a place full of bounty where no one can harm you. But in addition to that, it's based on the notion of exclusivity. All paradises, all utopias, are defined by who is not there, by the people who are not allowed in."

¿Dirías que buscabas una meta similar en Nietos cuando en Cumbres excluyes a las personas de tez blanca?

CGW: Claro, claro. Hoy día diríamos "non grata", y los excluí de ese país ficticio porque quería que los habitantes disfrutaran de un lugar bello y tranquilo donde estarían libres de los problemas del mundo real. Cumbres del Kilimanjaro es nuestro espacio, nuestro terruño, o nuestro fuerte contra todas fuerzas enemigas.

HZ: Un destino final similar a la tierra prometida de los judíos en la Biblia porque el narrador describe el lugar como la tierra promisoria para los nietos de Felicidad Dolores.

CGW: Exacto. Has leído con mucha atención; has analizado profundamente ese capítulo. No es cualquier lugar. Habrás notado que no es un desierto. Se trata de un territorio en las cumbres más altas, un lugar que queda fuera del alcance del enemigo. Es el concepto de la muralla china, la cual tenía el propósito de impedir que los bárbaros llegaran al corazón de la población. Planteo la misma idea en Cumbres del Kilimanjaro. Allí hay paz, tranquilidad 
y mucho orgullo porque es nuestro terruño. Ya no somos ciudadanos de segunda clase. Ahora pertenecemos a un grupo que nos aprecia, y ya no es necesario llevar tantas máscaras para poder sobrevivir. Eso roba mucha autenticidad.

HZ: No hay indicios sobre la ubicación de Cumbres. El lector no puede determinar si está en África o el Nuevo Mundo. Me pregunto si es un detalle más o se trata de una estrategia con la que comunicas la idea de home is what you make it, home is where you feel you are safe. Cumbres está conectado con África-esté o no esté en ese continente. La casa es donde uno se siente a gusto.

CGW: Exacto. Es la idea, ¿no? Así como los pichones tienen su paladar, yo quiero crear un lugar sagrado, un lugar seguro, un lugar donde se enfoca solamente en la esencia y no la estatura o el color del cabello, o sea, la hermandad.

HZ: La idea de la hermandad se sugiere claramente en la siguiente declaración, hallada en la penúltima página de la novela durante el estreno de la república de Cumbres: "Por fin, nosotros, los nietos de Felicidad Dolores nos hemos organizado. Sí, nosotros los afrolatinos estamos UNIDOS" (231). Puesto que es también el momento en que el lector descubre por primera vez el significado de la palabra SODINU, que es UNIDOS escrito al revés, ¿me imagino que querías llamarle la atención retroactivamente a la importancia de esa palabra, usada tan repetidamente a lo largo de la novela?

CGW: Exactamente. Gracias por analizar a ese nivel el concepto que quise desarrollar en la palabra SODINU. Yo temía que nadie lograra descifrarla, aunque es realmente la clave a la novela. La unidad es efectivamente nuestra salvación. Ahora, esa palabra [UNIDOS], ¿por qué la escribo al revés? Es para desarrollar cierta curiosidad en los lectores. Los que se acerquen al libro de esa forma van a descubrir que considero la unidad como el primer paso a la recuperación de todo lo ancestral que se nos fue destruido o negado. Sólo a través de ella vamos a redescubrir nuestra historia y nuestros valores.

HZ: Otro detalle que siempre me ha interesado es el título mismo-Los nietos de Felicidad Dolores. Ya me tomé la libertad en una ocasión, un congreso precisamente, para explicar que además de ser un título como cualquier título, en las obras de Carlos Guillermo Wilson, hay una tendencia a atribuirle un sentido a todos los detalles, como haría un buen cuentista. Por consiguiente, si bien la figura de Felicidad Dolores en Nietos es la Madre África, como le explicaste a Elba Birmingham-Pokorny, sostengo que la palabra "Felicidad" alude a los muchos triunfos que nuestra gente ha tenido en estas tierras, mientras "Dolores" se refiere a los numerosos abusos e injusticias que ellos también han tenido que aguantar. Los nietos de la Madre África hemos vivido muchos momentos tristes, pero también momentos agradables; y de ahí la dualidad "felicidad/dolores".

¿Qué opinas de esa lectura del libro?

CGW: Pues muy acertada. Y ese contraste o dualidad que experimentamos constantemente en la vida - noche y día-es lo que nos da la esencia. Cuando yo estaba en el seminario, muchas personas se asombraron de que lograra pasar cinco años en ese lugar con el espíritu rebelde que tengo. No entendieron cómo pude aguantar la forma no dualística en la que nos presentaban los misioneros tantas cosas en la vida. Pero bueno, tuve mis razones. Me serví de mi experiencia como negro para reinterpretar los hechos que me presentaban, sea la idea de la vida y la muerte u otro tema. Unos años más tarde tuve la oportunidad de viajar a Australia con mis compañeros de clase donde noté que los aborígenes hacían lo mismo. Cuando les hablamos de la nieve en Estados Unidos, de lo fría que es, ellos inmediatamente la asociaron con el fuego y el sol porque les dijimos que podía quemar esta cosa a pesar de ser fría.

HZ: Para concluir esta parte de nuestra plática, ¿qué opinas de la idea de la aldea global, la alegación de que la identidad étnica es irrelevante hoy en día porque el mundo está tan interconectado? ¿Crees que es un argumento válido o una simple ilusión quimera por parte de quienes prefieren ignorar la continua realidad del prejuicio racial y las diferencias culturales?

CGW: ¿Sabes? Es un concepto muy interesante; sumamente interesante. Cuando yo analizo o pienso en el concepto del "global village", estoy pensando en la experiencia que tuvieron los que sobrevivieron los barcos negreros, el hecho de que vinieron de tantas diferentes partes de África, pero no se pueden borrar completamente los ingredientes. Es como un sancocho que, a pesar de sus múltiples componentes, siempre sale muy rico y produce una nueva identidad. Veo la aldea global en términos similares. Es algo muy positivo porque aprendemos mucho de la tolerancia y la importancia de la hermandad. 
HZ: Me alegro que hayas tocado sobre el tema de la comida. En casi todos libros de Carlos Guillermo Wilson siempre hay referencias a arroz con guandú, mangos suculentos y jugosos, etc. La prevalencia de ese detalle en tus obras me indica que la comida no es un pormenor decorativo sino un detalle cultural, sobre todo, en el contexto caribeño. ¿Me quieres comentar sobre el detalle? ¿Qué significa la comida para ti como panameño y caribeño?

CGW: Creo que mi obsesión responde a la felicidad que me daban los platos que preparaba mi abuelita Nenén. Yo pasé los primeros sietes años de mi vida a su lado y siempre quería ingredientes frescos, nada congelado. Cuando íbamos al mercado, yo tenía que cargar la bolsa y si quería preparar un pollo o una gallina, tenía que ver y tocar la gallina. Los otros ingredientes también tenían que ser libre de defectos, entonces siempre olfateaba los tomates, la lechuga y hasta el ñame. O sea, todo fue cuidadosamente seleccionado. La preparación misma de la comida también seguía un ritual. Aunque nunca medía nada, como se hace ahora, todo salía perfecto porque tenía su método. Su única guía era una cuchara con que probaba la sal y el picante. En fin, así me nació el interés en la comida. Yo debería ser un gran chef, pero como no le presté suficiente atención a ella, me quedé solamente con las memorias que cuento en mis libros.

HZ: Entonces todo se hacía siguiendo el método ancestral.

CGW: Exacto. Y los niños sólo pensábamos en lo rico que iba a salir todo, cómo íbamos a chuparnos los dedos.

HZ: Según lo que estoy escuchando, parece que la comida se usaba en tu familia como un foco para el desarrollo de lo humano, o sea, un pegamento social a través de la cual la gente desarrollaba sus relaciones sociales.

CGW: Exactamente. Es una manifestación de la felicidad, una de las mejores definiciones de ese sentimiento en el ser humano. Yo paulatinamente fui captando la importancia de esa manifestación en la esencia de la cabanga africana. Por lo tanto, te repito que atinaste muy bien en observar ese detalle en mis obras. Es parte de la herencia ancestral en el ámbito de la comunicación que se ha ido perdiendo. Aún recuerdo cómo mi abuela Nenén reaccionaba cada vez que yo le decía "Granny" (Grandma) en la cocina o cualquier otra parte de la casa. Siempre me miraba con mucho más cariño y entablaba conmigo algunas de las conversaciones más placenteras que aún guardo de mi infancia. Sólo con escuchar la palabra, no importa en presencia de quién, ella siempre me concedía todo lo que yo quería. Era entonces un refugio para mí en mi niñez, una manera especial de introducirme en el mundo interior de mi abuela.

HZ: Ahora que estamos hablando de "Granny", yo tuve la suerte de leer un documento autobiográfico que me enviaste en el año 2000 donde descubrí por primera vez que "Granny" es Lena McZeno, a quien conocen tus lectores como Nenén. Otra persona que también descubrí en el documento, un individuo sumamente importante para ti que no hemos discutido todavía en esta entrevista, es James Duglin, quien va por el nombre de Papá James en tus libros. A continuación, tenemos a Abena Mansa Adesimbo, quien, en la vida real, es tu madre Henrietta Wilson de Wagner. Quisiera que compartieras con tus lectores que significan estas tres personas para ti porque prevalecen en Chombo y vuelven a aparecer en Nietos y Misión. Lo dejaste muy claramente en el documento antes mencionado que son individuos que te moldearon la vida. ¿Quieres compartir con tus lectores las historias de esos tres ángeles? ¿Cuál fue la relación entre tú y ellos? Tengo aquí fotos de los tres por si te despierten la memoria.

CGW: (Pausa larga) Pues, Maabiinu, como has observado en la pausa, en todo lo que yo escribo, busco una manera de presentar a las tres personas claves en mi vida. Puedo darte lujo de detalles, pero no sé si el tiempo lo permita, porque es una historia extraordinaria que siempre me ayuda cuando recuentro la esencia de lo que es fraternidad y amor, la bondad en el ser humano. Para mí, ellos son los mejores ejemplos de esos sentimientos en este mundo-los veo como la Santa Trinidad. Es un simbolismo muy importante en la religión católica-la familia, lo que regala lo esencial de la vida, el techo para sentir tranquilidad y felicidad. Mi granfara (grandpa), Papá James, siempre fue el ancla de la familia. Todo el vecindario le decía Papá James porque era tan amable. Era pintor de brocha gorda, pero tenía un grupo de hombres que lo ayudaban para pintar edificios y negocios de panameños muy acaudalados. Logró establecer el negocio con ellos aun siendo niño. Uno de los clientes era la Familia Toledano, españoles de ascendencia judía, de la ciudad de Toledo, quienes a lo mejor llegaron a 
Panamá después de la expulsión de 1492. Mi abuelito James Duglin vino de Barbados para participar en la construcción del Canal. Por su parte, mi abuelita Lena McZeno, o “Granny”, llegó de Jamaica. Los dos alquilaron una casa en la Avenida B, en la vecindad de Guachapalí-Parañón en Ciudad de Panamá, donde recogían a los niños más necesitados del vecindario y los alimentaban con el negocio de comida que tenía mi granny. Pronto llegó a conocerse entre los afroantillanos como "la Casa 12, entre la Calle 20 y la 21 de la Avenida B, donde viven Papá James y Nenén", nombre que en el inglés jamaiquino quiere decir "madrina". Pero la Casa 12 también tenía otra fama. Era donde encontrar al hombre con más enchufes que cualquiera en la vecindad, el hombre que ayudaba a todos los afroantillanos recién llegados a la ciudad que buscaban empleo: mi abuelo Papá James.

HZ: ¿Entonces Papá James y Nenén se conocieron por primera vez en Panamá?

CGW: Exacto-por el canal. Sin él, hubiera sido imposible que se conocieran.

HZ: En una ocasión mencionaste que Papá James traía dulces a ti y los otros niños diariamente.

CGW: Sí. Yo, afortunadamente tuve una niñez con mucha felicidad y cariño. Entonces llegó el dolor. Todo lo que yo escribo efectivamente tiene rasgos autobiográficos. Ya sé que muchos rechazarán autobiografía en una novela, pero para mí, no hay mejor ejemplo para explorar el concepto de la felicidad. Así como en la vida real tenemos azúcarsal, día-noche, esa dualidad se repite constantemente en mis obras, ¿verdad?

HZ: Pues, en cuanto a los elementos autobiográficos te digo que eres el mejor representante de lo que Richard Jackson llama "public servants" en la literatura afro-hispana. Los escritores en esa literatura tienden a ser servidores públicos, los cuales define él como las personas que dan voz a los que no la tienen. O sea, la voz de grupos marginados como los afroantillanos en Panamá y los afrolatinos, en general. En ese sentido tú sigues la larga trayectoria de aquellos escritores afro-hispanos que se han enfocado en la realidad vivida de sus lectores implícitos, en su lucha diaria contra el hambre y la injusticia en vez de inventar realidades extra mundiales en nombre del arte por el arte.

\section{CGW: [Sonrisas]}

HZ: Abena Mansa Adesimbo, conocida en la vida real como tu mamá Henrietta Wilson de Wagner, es una de las tres personas que influyeron mucho en tu vida. Lamentablemente, falleció hace poco, pero veo fotos de ella en todas partes de la casa inclusive, el lugar más sagrado para ti--tu recámara. Eso me dice que no se trata simplemente de recordarla sino un esfuerzo tuyo para mantener un vínculo con el mundo que dejaste atrás. ¿Me equivoco?

CGW: Pues no. Tienes razón. Has atinado en otro detalle clave de mi vida.

HZ: En una conversación hace ya tiempo, me informaste que viajaste a Jamaica en tres distintas ocasiones en busca de tus raíces caribeñas. ¿Quisieras compartir los resultados de esos viajes con tus lectores?

CGW: [Larga pausa] Vuelvo a agradecerte tu interés en mis obras. Escribir es una actividad solitaria. Yo paso hora, días, meses, años, pero no es un castigo porque estoy tratando de hacer un aporte para llenar un vacío en la literatura latinoamericana y panameña así que es casi una obsesión. Hoy día hay tantas distracciones que no es posible dedicarse uno a tantas actividades en comparación con la responsabilidad que me han dado, mejor dicho, ordenado mis antepasados. Ellos quieren que yo divulgue la historia de mi gente, que asegure que no se olvide nunca esa historia, sea los horrores de la trata transatlántica misma o los abusos que han sufrido y siguen sufriendo los descendientes de las víctimas directas.

HZ: Entonces el viaje a Jamaica tenía el propósito de conectarte con esa historia que empezó en África, pasando por Panamá, y que terminó metafóricamente en Jamaica. Tenías, como quien dice, que ponerle puntos a las "i" y cruzarle las "te".

CGW: Exacto. Tuve esa sensación de que algo faltaba. Entré en un estado de sonambulismo. Por muy cansado que estuviera, no podía dormir. Absolutamente nada de sueño. Me pregunté por qué sería eso. Entonces se me ocurrió que a lo mejor me hablaban los antepasados, que querían que yo escribiera sobre la historia ignorada de mi pueblo. Al principio, yo simplemente escribía palabras y párrafos en el papel. Nunca componía historias enteras. Eso vino después, cuando empecé a reconstruir eventos completos, primero en la mente antes de 
pasarlos a papel. Nunca usaba pluma hasta después de estar satisfecho. Y aun así, siempre distinguía entre los diferentes colores. Por ejemplo, la tinta azul significaba que lo escrito todavía necesitaba mucha revisión. El color rojo quería decir que me quedaba solamente buscar una que otra palabra. Cuando estaba cien por ciento satisfecho, como en que "esto ya no puede mejorarse más", entonces lo pasaba al color verde. Imprimía el borrador sólo en este punto.

Escribir Chombo fue lo más difícil, pero el proceso se fue aligerando con los próximos libros. Y debo agregar que siempre me sentía acompañado por los antepasados. Sentía su presencia cada vez que escribía. Entonces he tenido una odisea bien larga, pero la considero un honor. "Hay que mejorar la raza", me digo.

HZ: Entonces los ancestros son un llamado a narrar la historia de tu gente, o sea un tema y una musa al mismo tiempo.

CGW: Indudablemente. Al principio pensé que era un talento personal, pero luego me di cuenta de que los ancestros me impulsaban.

HZ: Si te estoy escuchando bien, la historia ocupa un sitio central en tus libros ya que la vemos en los muchos episodios históricos que en ellos se cuentan y en los comentarios que hiciste sobre el tema en la entrevista con Elba Birmingham-Pokorny. Sin embargo, me pregunto, ¿por qué te interesa tanto? ¿Será porque ves la historia como una herramienta para promover y facilitar cierto entendimiento de la vida?

CGW: Me alegro que me hayas hecho esa pregunta porque siempre he querido anunciar a nuestra gente y a todos los otros grupos que aquí está el mapa o la historia de nuestros antepasados. Pero como fue una historia suprimida durante siglos, es difícil contarla fielmente. Por eso acudo a las experiencias de mis personajes. A través de esas experiencias, trato de reconstruir la historia de los antepasados porque las considero como parte del continuum. Y te cuento que todo empezó en una clase de literatura. Me enojé mucho cuando el profesor declaró con harta convicción que Colón descubrió las Américas. ¿Cómo las descubrió si ya había millones de personas aquí con sus instituciones y sus pirámides? Yo escribo, pues, para llenar esas lagunas, completar la historia para que sea verdadera.
HZ: Entonces, es lógico suponer que los episodios históricos en tus libros se encaminan a insertar a tus lectores implícitos en la historia nacional de sus respectivos países de nacimiento, a reinscribirles en ese discurso del que antes fueron excluidos porque la veracidad histórica siempre la determina el que la compone. Si es una verdad falsa o deformada, la única forma de corregir la mentira es asumir el papel de historiador.

CGW: Exactamente.

HZ: En ese caso te has unido a una larga línea de ekobios, como diría Manuel Zapata Olivella, que han intentado hacer lo mismo: Candelario Obeso, Nicolás Guillén, Adalberto Ortiz, Nelson Estupiñán Bass, Nicomedes Santa Cruz, Virginia Brindis de Salas, Nancy Morejón, Quince Duncan, Eulalia Bernard y Cristina Cabral, para mencionar solamente unos ejemplos. Todos se metieron en la literatura precisamente para corregir esas imágenes falsas y distorsionadas que se han venido propagando desde el siglo XVI acerca de los pueblos negros.

CGW: Sí, así es.

HZ: Una interpretación muy oportuna en tu caso no sólo para los afroantillanos en Panamá sino también todas las comunidades negras de las Antillas cuyas historias también fueron distorsionadas o extirpadas totalmente del discurso oficial de sus respectivos países de nacimiento.

CGW: Has logrado captar muy bien ese concepto. Es un llamado de los antepasados a terminar de corregir y enriquecer nuestra historia. $\mathrm{Y}$ ahora, a los 73 años y además enfermo, temo desaparecer antes de cumplir con la misión-sería un insulto a ellos. Establecieron la fundación o el punto de arranque de esta odisea y yo tengo que cumplir con mi parte.

HZ: Es interesante que digas eso porque se conecta con un comentario que salió en el documento autobiográfico que comentaba antes. Es sobre Chombo y reza lo siguiente: "Mi primera novela Chombo fue escrita a la carrera porque extrañamente a diario me preocupaba mucho con la obsesión de morir antes de narrar la novela que ya había desarrollado en mi mente. En aquel entonces todo me fastidiaba porque consideraba el comer, dormir y trabajar como distracciones fastidiosas que me quitaban el tiempo para poner en papel todo lo que tenía escrito en mi mente. Además, todo me impacientaba angustiosamente menos escribir. Sufrí 
mucho por la obsesión con la muerte, morir antes de dar a conocer públicamente lo que había narrado en mi alma".

CGW: Gracias a Dios sobreviví esos años. [Risitas]

HZ: Hablemos ahora de tus libros en general. Mencionamos al principio de esta entrevista que empezaste con Cuentos del Negro Cubena, el cual fue seguido de Pensamientos, Chombo y Nietos en ese orden. Estabas trabajando sobre la última parte de Misión cuando se te dio la embolia. ¿Quisieras comentar sobre Chombo y Nietos? En tu opinión, ¿̇en qué manera son diferentes?

CGW: Son muy diferentes en el aspecto de que Chombo es una obsesión de presentar como mejor pueda una historia personal. Es una autobiografía disfrazada como novela, pero realmente es mi infancia. Ahora, en Nietos hay una madurez porque ya no siento esa obsesión de que, si muero mañana o esta noche, todo esto se va a perder, como suele ocurrir en la realidad. Me refiero al hecho de que muchas personas a menudo tienen información valiosa que quisiera documentar para la posteridad, pero por falta de la tecnología correcta (CDs, computadoras), no lo pueden hacer. La gran diferencia entre Chombo y Nietos es entonces que Chombo fue escrito a una velocidad vertiginosa porque me temía morir sin contar la historia que ya tenía narrada en mi mente. En cambio, con Nietos, ya estaba más calmado. Aunque ese libro también tiene aspectos autobiográficos, tiene más creatividad, y tanto tú como el Dr. Ian Smart lo han señalado.

HZ: Bien, otra observación que yo tengo sobre Chombo es el carácter mismo o el alcance de la historia que en ella se narra. Para mí, es como una pelea familiar, una crítica de las relaciones conflictivas que existen entre los negros coloniales y los afroantillanos dentro de Panamá. Pero ya cuando uno llega a Nietos, esa pelea ha salido de la familia y se ha estallado en la calle, como quien dice, la cual podría verse como una metáfora del Nuevo Mundo. Si bien en Chombo los malentendidos familiares se limitan a la América Central y el Caribe, en Nietos van a ir más allá de esa región para abarcar el continente africano, la América del Sur y Norteamérica. Por consiguiente, es una visión más amplia que la que se ha propuesto en Chombo.

CGW: Exacto.
HZ: Entonces, ¿cuál sería el pegamiento temático entre esas primeras dos novelas (Chombo y Nietos) y Misión, la cual, si Dios quiere, vamos a publicar pronto? Puesto que es la conclusión de una trilogía que empezó con Chombo y cada trilogía forma un continuum, ¿cuál, en tu opinión, es ese continuum?

CGW: El punto de arranque es el hecho de que estoy realmente reescribiendo a Chombo en Nietos, y a esos dos libros en Misión. He vivido más y tengo más experiencia. También he leído más y tenido mayor contacto con los ekobios. Por consiguiente, ya no me limito a mi grupo étnico (los afroantillanos). Ahora, tengo una visión más amplia del concepto de la hermandad; he tenido la oportunidad de conocer a otros seres humanos que han dado más valor a mi vida—negros cubanos, garífunas hondureños y guatemaltecos, africanos de la Madre Patria.

Ellos han vivido las mismas experiencias que yo así que no importa que tengan otros apellidos o que hablen otros idiomas. La similitud de nuestras experiencias nos une. Todos hemos vivido las mismas humillaciones. Como resultado, mi lucha para conseguir justicia para mi pueblo debe incluir a ellos también.

HZ: Siguiendo con Misión, he notado que hay muchas referencias a la cultura garífuna, sobre todo el idioma, que en mi opinión es parte del ensanchamiento de la tienda familiar que empezaste en Nietos. Pero ya pasando a esta tercera novela, ampliarás esa tienda aún más para abarcar al pueblo garífuna que, como decías antes, son parte de nuestra familia o comunidad de oprimidos que fue extirpada de la historia global. ¿A qué obedece esta ampliación de tu mundo novelesco?

CGW: Me alegro de que te haya llamado la atención ese aspecto del libro. Es muy importante. En cuanto a tu pregunta, la respuesta es obvia. Los garífunas también han sido víctimas de la odisea o tormenta que nos tocó vivir los negros en estas tierras. También han sido oprimidos y marginados por su apariencia física y su historia. Ni siquiera la reciente decisión de la ONU a nombrar la cultura garífuna como un patrimonio de la humanidad ha cambiado esa situación. Yo los celebro porque creo que, junto con los haitianos, ellos son algunos de los ekobios que más han luchado para preservar los recuerdos ancestrales en estas tierras. Mi fascinación con la cultura me llevó hasta a aprender el idioma garífuna y a sostener conversaciones con 
muchas personas de esa cultura, principalmente de Guatemala y Honduras, porque quería saber más sobre ellos.

HZ: La idea de incluir a los garífunas en Misión me parece muy lógica porque como conclusión de una trilogía que pretende poner de manifiesto la totalidad de la experiencia negra en el Nuevo Mundo, sería una obra incompleta sin ese grupo ya que son mitad negro y mitad indígena. Y que yo sepa, Misión es la primera novela afro-hispana que aborda el tema.

CGW: Sí. Exacto. Y como dije hace un rato, yo siempre he tenido asociación con las lenguas porque es una de las maravillas del ser humanopoder expresar la misma idea con otro acento o vocabulario. Eso enriquece la comunicación.

HZ: Bien, continuando con el tema general de Misión, la última frase de la novela es "iViva Panamá!", palabras que claramente sugieren un acercamiento emocional al país por parte de su autor. Puesto que la Panamá que retratas en Chombo y Nietos es un lugar repleto de odio y divisiones raciales, ¿dirías que en Misión estás anunciando una nueva Panamá, un país que ya no es igual que el que estrenaste en 1977?

CGW: Efectivamente. Misión se enfoca en la Panamá de finales del siglo veinte y los comienzos del actual-el siglo XXI. Aunque algunos de los problemas que desató la Constitución de 1941 bajo el Presidente Arnulfo Arias aún persisten, no puedo negar que se ha adelantado mucho nuestro reto y que hay una mayor concientización o reconocimiento de los aportes de nuestro pueblo ahora. Como tú y todos los lectores de Chombo ya saben, esa constitución les negó la ciudadanía a muchos panameños de ascendencia antillana, mi mamá inclusive, simplemente porque ellos tenían parientes nacidos fuera de Panamá. Por lo tanto, cuando en agosto de 2002 la Presidenta Mireya de Moscoso me condecoró a mí y a 8 otros panameños, en su mayoría afroantillanos, con el Orden de Vasco Núñez de Balboa, el reconocimiento civil más alto en Panamá, para agradecernos nuestros aportes a la cultura nacional, llegué a la conclusión de que el país había empezado a cambiar para bien. Pero tal vez la ceremonia no tuviera tanto simbolismo si no fuera por quien la dirigió. Por si no lo sepas, la Señora de Moscoso es la viuda del Dr. Arnulfo Arias, el mismo señor que engendró la constitución del 1941. Por lo tanto, su decisión nos demostró a todos los panameños, pero en especial a los de ascendencia antillana, que en Panamá había nacido un nuevo día-un día en que ahora éramos todos iguales ante la ley. No obstante, eso no quiere decir que es un país totalmente libre de conflictos raciales ahora. Aún queda camino que recorrer.

HZ: Hay otro detalle que iba a saltar, pero no puedo resistir. Se trata de la representación de Hernán Cortés en Misión. Me llama mucho la atención porque me recuerda Todos los gatos son pardos, una obra teatral de Carlos Fuentes donde el famoso conquistador y la Malinche salen reivindicados. En esa obra, Cortés ya no es el pillín que conocemos en los libros de la historia sino un hombre que gracias a la influencia de la Malinche, tiene ahora cualidades positivas. Noto un tratamiento similar en Misión donde lo presentas como un defensor de los indios y los negros a causa de su larga amistad con su acompañante negro Juan Garrido. Al igual que en la obra de Fuentes, es ahora un blanco racional que rechaza los estereotipos hacia esos dos grupos raciales y los pone casi en el mismo plano moral como sus compatriotas. ¿Qué mensaje querías comunicar con ese retrato del conquistador de los Aztecas?

CGW: Que a pesar de los insultos, los golpes y la letanía larguísima de humillaciones que hemos sufrido como pueblo, hay esperanza. Tenemos que tener fe en la capacidad de todos los seres humanos inclusive Hernán Cortés, de elegir el bien sobre el mal si así lo deciden. Obviamente, no quiero decir con eso que creo en construir castillos en el aire, pero sí creo en los sueños-en la esperanza.

HZ: Yo creo que esa es la palabra clave. Misión es efectivamente una novela muy esperanzadora. Y parte de esa esperanza reside no solamente en reconciliar a los diferentes grupos étnicos sino también en reconstruir la historia de las Américas de tal manera que se libere de las imágenes tan negativas y violentas que siempre han sido parte de ella. En ese sentido la imagen de Cortés que uno encuentra en la novela cabe perfectamente dentro de ese proyecto.

CGW: Sí, pero todavía falta mucho camino que recorrer. Aún nos falta mucho que hacer, pero como dice el proverbio chino, un viaje de mil millas empieza con el primer paso. Ya se ha dado el primer paso por el reto que nosotros hemos hecho para 
enriquecer a Panamá, nuestra patricia y nuestro terruño, pero dure lo que dure el resto del camino, "Viva Panamá!"

HZ: Finalmente, muchos de tus lectores ya saben, al menos los de Chombo, que estuviste en dos seminarios, Saint Augustine en Mississippi y Divine Word en Massachusetts, donde por poco te haces cura. La pregunta aquí tiene que ver con los muchos comentarios anticlericales que se notan en Chombo y Nietos. En Chombo, por ejemplo, el narrador se burla de las oraciones latinas con que el cura bautiza a Litó. En otra parte de la novela le cambia el apellido del Padre de las Casas a "las Chozas", o sea, "Bartolomé de las Chozas". Más allá de los hechos históricos, el hecho de que muchos crímenes se han cometido a lo largo de la historia en nombre de Dios inclusive la decisión del fraile dominicano a recomendarles a los reyes españoles la importación de esclavos africanos a estas tierras para salvar a los indígenas, ¿a qué obedece este desprecio o hostilidad hacia la Iglesia Católica? ¿Acaso te pasó algo feo en uno o los dos seminarios mientras estudiabas allí?

CGW: Sí, es algo que he logrado presentar en varios sitios, en varios lugares de la novela. Unas amargas experiencias, ¿verdad? Yo siempre pienso que por algunas experiencias en el seminario, yo perdí mi catolicismo. ¿Cómo es posible que teniendo la oportunidad de enseñar, de ser un modelo, la pierdan tantos curas? Ha sido una experiencia con muchas manchas. Y lo seguimos viendo aún hoy en día. Como ya sabes, la Iglesia fue obligada recientemente a abrir las ventanas para que entre el aire, a admitir que algunos de sus miembros, precisamente los que han sido responsabilizados con guiar a nuestros hijos, los han traicionado. Pero me anima lo que está haciendo el Papa Francisco con su acercamiento a los otros sistemas de creencia y su empeño en proteger a nuestros niños. Ojalá no sean acciones superficiales encaminadas tan sólo a sofocar la crítica. De todos modos, hay que seguir criticando la hipocresía y la falta de hermandad que tanto predica la Iglesia.

HZ: Otra vez, muchas gracias por recibirme en tu casa y por concederme esta entrevista. Espero que aporte algo nuevo al conocimiento que ya tienen tus lectores y críticos sobre tus libros.

CGW: Y gracias a ti por darme esta oportunidad para dialogar sobre algo que es tan importante para mí. Tus preguntas hoy y las conversaciones telefónicas que hemos tenido a través de los años me han hecho reflexionar sobre aspectos de mis libros que antes ignoraba o simplemente se me habían olvidado. Gracias por ampliar y subrayarlos hoy.

HZ: Fue un placer. Gracias otra vez.

\section{Dr. Haakayoo Nobui Zoggyie Morehouse College}

\section{Endnotes}

${ }^{i}$ Poco después de enfermarse, Carlos me envió el manuscrito para terminar las revisiones que él le estaba haciendo. Logré lo pedido pero no tuve tiempo para finalizar los trámites de la publicación antes de que falleciera. Ahora, necesito conseguir el permiso de su familia para poder continuar con el proyecto. Si Dios quiere, el libro saldrá publicado en 2018. 